\title{
Estudo das vogais médias pretônicas /e/ e /o/ do português urbano de Cametá-PA: análise dos dados da primeira faixa etária
}

\author{
Study of pretonic mid-vowels /e/ and / o/ of urban portuguese from Cametá-PA: \\ analyzing data of first age group
}

\author{
Josivane do Carmo Campos Sousa ${ }^{*}$ \\ Universidade Federal do Pará \\ Belém, Pará, Brasil
}

Regina Célia Fernandes Cruz ${ }^{* *}$

Universidade Federal do Pará

Belém, Pará, Brasil

\begin{abstract}
Resumo: O presente artigo tem como objetivo caracterizar acusticamente as vogais médias pretônicas - /e/ e /o/ - no português falado na área urbana de Cametá-PA, segundo os parâmetros de F1 (em Hz), F2 (em Hz), F3 (em Hz) e Duração (em ms). Os procedimentos metodológicos foram estabelecidos por Cruz (2011): a) corpus padronizado; b) amostra estratificada (sexo, faixa etária e nível de escolaridade); c) coleta de dados por meio da leitura de texto; d) tratamento de dados no programa Praat; e) cálculo de média e representação por gráficos com o programa Excel. A amostra constitui-se de 03 homens e 03 mulheres com idade entre 15 e 25 anos, com escolaridade fundamental, médio e superior. Foram analisados 232 dados obtidos do tratamento de 06 sinais sonoros com duração total de $32 \mathrm{~min} 06$ s de gravação. Os resultados mostraram que, quanto ao espaço acústico formado com as médias de F1 e F2, há maior proximidade entre as variantes altas e médias, e maior distância entre as variantes médias e baixas, exceto na fala masculina em que as três variantes anteriores se encontram bem próximas. O parâmetro de F3 se mostrou como parâmetro de identidade das variantes, demonstrando que o nível acústico é um espelho do nível fonológico, uma vez que a proximidade entre as médias das frequências das variantes demonstra que não se tratam de fonemas diferentes, mas das diferentes realizações de um mesmo fonema. Quanto à Duração, verificou-se que as variantes abertas e baixas são mais longas que as variantes médias e altas, comportando-se assim como um parâmetro que caracteriza as vogais por seus aspectos duracionais capazes de estabelecer distinções entre as variantes.
\end{abstract}

Palavras-chave: Amazônia paraense. Análise acústica. Vogais médias pretônicas.

\begin{abstract}
The aim of this paper is to characterize acoustically the pretonic mid-vowels - / e / and /o / - in the Portuguese spoken in the urban area of Cametá-PA according to the parameters of F1 (in Hz), F2 (in Hz), F3 in $\mathrm{Hz}$ ) and Duration (in ms). The methodological procedures were established by Cruz (2011): a) standardized corpus; b) stratified sample (sex, age group and schooling level); c) data collection through text reading; d) data processing in the Praat program; e) calculation of mean and graphical representation with the Excel program. The sample consisted of 03 males and 03 females aged between 15 and 25 years old, with fundamental, average or higher schooling. We analyzed 232 data obtained from the treatment of 06 sound signals with total recording
\end{abstract}

*Doutoranda do Programa de Pós-Graduação em Letras - PPGL - Universidade Federal do Pará, Belém, Pará, Brasil. E-mail: doutorado.2016@gmail.com.

** Professora do Programa de Pós-Graduação em Letras - PPGL - Universidade Federal do Pará, Belém, Pará, Brasil. E-mail: reginafcruz@gmail.com. 


\section{das Letras}

duration of 32min06s. The results showed that, for the acoustic space formed with the means of F1 and F2, there is greater proximity between the high and medium variants, and a greater distance between the medium and low variants, except in the male speech where the three previous variants were found very close. The parameter of F3 was shown as the identity parameter of the variants, demonstrating that the acoustic level is a mirror of the phonological level, since the proximity between the means of the frequencies of the variants demonstrates that they are not different phonemes but of the different realizations of the same phoneme. Regarding the duration, it was verified that the open and low variants are longer than the medium and high variants, thus behaving like a parameter that characterizes the vowels by their durational aspects capable of distinguishing between the variants.

Keywords: Amazônia from Pará. Acoustic analyse. Pretonic mid-vowels.

\section{INTRODUÇÃO}

O presente artigo tem como objetivo apresentar os resultados parciais da investigação acústica do sistema vocálico do português falado na Amazônia Paraense, tomando como objeto de estudo as vogais médias pretônicas /e/ e /o/ e suas variantes (Figura 1) no português falado na área urbana da cidade de Cametá/PA (SOUSA, em andamento) ${ }^{1}$.

Figura 1 - Variável dependente e suas possíveis variantes ${ }^{2}$

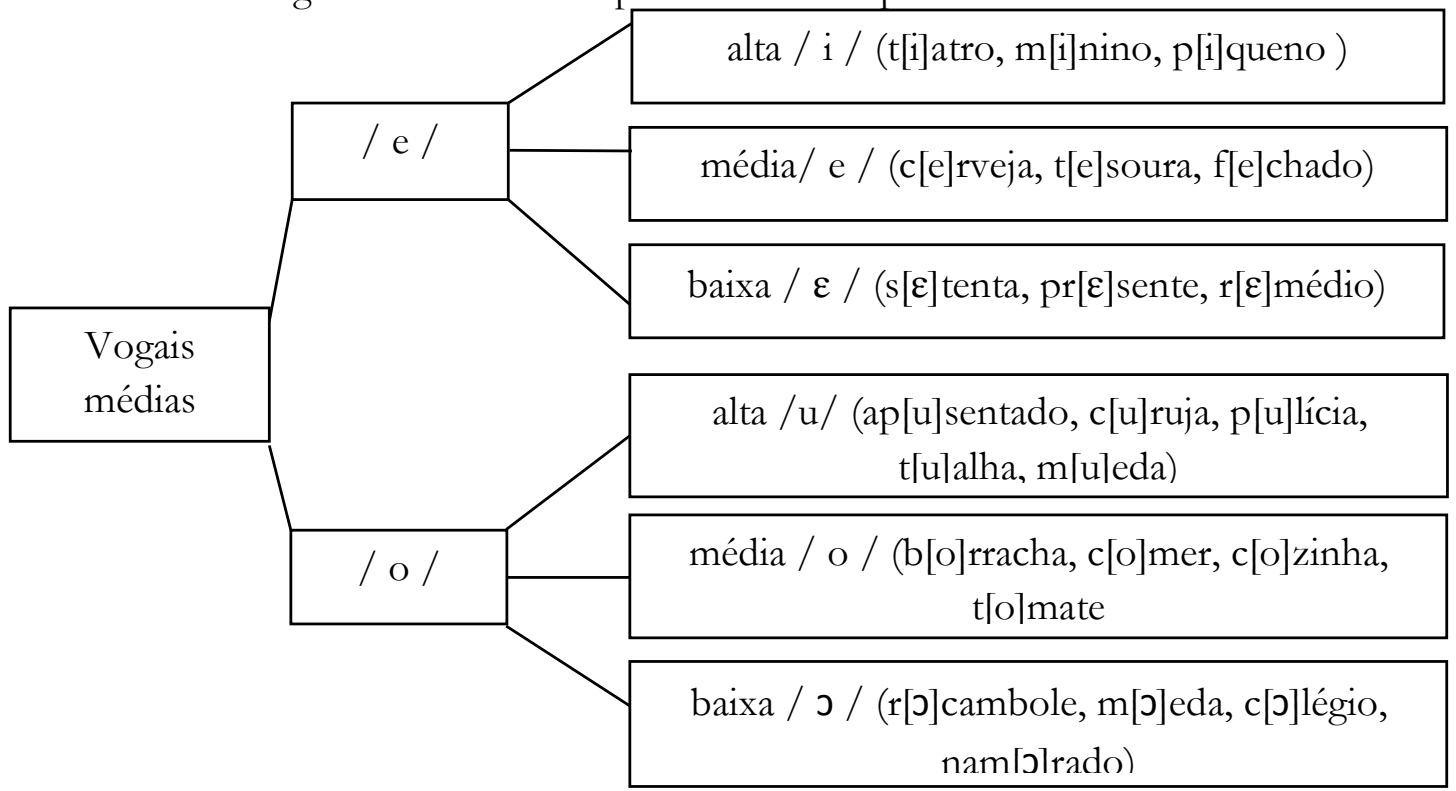

${ }^{1}$ O projeto está inserido na linha de pesquisa "Caracterização Acústica do Sistema Vocálico do Português da Amazônia Paraense" vinculada diretamente ao Projeto de Pesquisa Norte Vogais (Segunda Versão Portaria No 045/2016 ILC), sob Coordenação da Profa. Dra. Regina Cruz.

2 A transcrição é feita por meio do Speech Assessment Methods Phonetic Alphabet - SAMPA (Alfabeto fonético dos métodos de avaliação da fala). 
Fonte: Adaptado de Sousa (2010, p. 53)

A variedade do português falada em Cametá é uma das mais descritas da Amazônia Paraense em termos sociolinguísticos (RODRIGUES, 2005; RODRIGUES E ARAÚJO, 2007; COSTA, 2010; COSTA E CRUZ, 2012; RODRIGUES E REIS, 2012). Quanto à abordagem acústica, o trabalho pioneiro realizado sobre a variedade cametaense é o de Moraes (2015), que, buscando o refinamento das análises variacionistas, investigou as vogais médias pretônicas orais /e/ e /o/ no falar da zona rural segundo os parâmetros acústicos do Primeiro (F1) e do Segundo (F2) Formantes, de modo a fornecer uma referência do espaço acústico das vogais em análise. Por último, tem-se o trabalho de Souza et all (2015), no qual foram estudadas comparativamente as vogais médias pretônicas /e / e /o/ das variedades de Barcarena, Belém e Cametá (rural) com o objetivo de caracterizar as vogais orais átonas do português falado no Estado do Pará segundo o parâmetro físico da frequência fundamental (F0) intrínseca.

Com este trabalho, objetiva-se, portanto, realizar a caracterização acústica das vogais médias pretônicas /e/ e /o/ no português falado na área urbana da cidade de Cametá (PA), acompanhando a tradição de medir F1 e F2, mas introduzindo o Terceiro Formante (F3) e a Duração, tudo visando uma caracterização mais completa do sistema vocálico pretônico da variedade cametaense.

\section{REFERENCIAL TEÓRICO}

Para a análise acústica aqui apresentada, tomou-se como ponto de partida a teoria linear fonte-filtro da produção da fala apresentada por Kent e Read (2015), os quais tiveram como objetivo resumir essa teoria a partir de Fant (1970) e Stevens e House (1961). Para os autores, a importância da teoria fonte-filtro está em possibilitar a compreensão das relações acústico-articulatórias, bem como fornecer fundamentos para muitos procedimentos necessários a uma análise acústica. "O ponto crucial desta teoria é que os sons da fala podem ser entendidos em termos de uma fonte de energia que é filtrada pelo trato vocal" (KENT; READ, 2015, p. 93).

Kent e Read (2015) discutem a teoria acústica da fala contemplando as principais classes de sons. No entanto, foca-se aqui nas vogais, que, segundo os autores, são

sons produzidos com vibração laríngea (de modo que o vozeamento é a fonte de energia) e com o trato vocal relativamente aberto, modificado para produzir padrões específicos de ressonâncias (de modo que o trato vocal inteiro funciona como um filtro, ou um sistema de transmissão selecionador de frequências). (KENT; READ, 2015, p. 38)

Assim, o vozeamento é a fonte de energia, e o trato vocal é o filtro selecionador de frequências. Para ilustrar essa relação, toma-se a ressonância de tubos como modelo de produção da fala, a fim de evidenciar que as frequências de ressonâncias dependem do comprimento do tubo: tubos mais longos têm tons mais baixos, enquanto os mais curtos 
têm tons mais altos. Similarmente, pode-se explicar a razão das mudanças nas frequências de ressonâncias do trato vocal na mudança de criança para adulto.

As frequências de ressonância variam de acordo com o comprimento do trato vocal, que é determinado pelas características do falante. E os dois principais fatores, segundo Kent e Read (2015), são idade e sexo. Daí porque a análise dos dados do presente trabalho será apresentada conforme estes dois fatores.

Considerando, pois, que o espectro laríngeo das vogais possui a maioria da energia nas frequências mais baixas, bem como o que reafirmam Barbosa e Madureira (2015, p. 171) de que são "os dois ou três primeiros formantes que determinam a qualidade da vogal”, justifica-se a seleção dos três primeiros formantes para a caracterização acústica das vogais alvo do presente estudo.

F1 e F2 demandam um tratamento conjunto para a constituição do espaço acústico de vogais, uma vez que a frequência de F1 é inversamente relacionada à altura da língua do falante no momento da articulação de um fonema. E a frequência de F2 está diretamente relacionada à anterioridade ou posterioridade da língua, sendo essa frequência maior quando a língua está mais avançada e menor quando está mais recuada.

Parâmetro inédito nas investigações acústicas do português falado na Amazônia Paraense, F3 se refere à participação dos lábios na produção das vogais, e visando o avanço das investigações acústicas, também foi selecionado segundo o que afirmam Kent e Read (2015, p. 72): “uma razão é que a energia da fonte (o espectro laríngeo) é maior nas frequências baixas que incluem esses três primeiros formantes. Além disso, esses três formantes são suficientes para lidar com a maioria das variações fonéticas para as vogais das línguas do mundo".

O estudo do terceiro formante vocálico é importante para evidenciar as mudanças de frequência em razão das variações que são determinadas pelo formato do trato vocal, pois, como descreve a teoria da perturbação, as mudanças nas frequências dos formantes resultam de constrições locais do ressoador de tubo (KENT; READ, 2015). Neste sentido, o arredondamento dos lábios tem como efeito o abaixamento das frequências dos sons vocálicos, uma vez que o efeito desse arredondamento é o alongamento do trato vocal. Assim, "quanto maior o comprimento, mais baixas serão as frequências de formantes” (KENT; READ, 2015, p. 54). Por isso, as vogais arredondadas tendem a frequências de F3 mais baixas que as vogais não-arredondadas.

Em Stevens (1998), encontra-se o arredondamento dos lábios como uma característica que aumenta a proeminência de um pico espectral. Ao apresentar o quadrilátero mostrado na Figura 2 abaixo, são mostradas as possibilidades de como os formantes podem mudar quando um tubo acústico passa por diferentes formas de perturbações.

Figura 2 - Gráfico bidimensional representando as possibilidades de mudanças nas frequências dos primeiro e segundo formantes 


\section{das Letras}



Fonte: Stevens (1998, p. 285)

As setas partem de um ponto central indicando como as frequências de referência mudam quando o tubo é modificado por constrições em relação ao ponto de articulação. Os quatro cantos representam as vogais mais extremas que podem ser produzidas com o movimento da língua e arredondamento dos lábios.

Segundo o autor, consideram-se vogais extremas por não ser viável produzir frequências dos dois primeiros formantes fora do quadrilátero, já que seria necessário uma constrição muito estreita no trato vocal que não mantivesse uma vogal bem formada.

No entanto é possível produzir categorias vocálicas pela manipulação apropriada de estruturas articulatórias, de modo a produzir pontos dentro ou fora do quadrilátero. Uma destas manipulações é modificar o arredondamento dos lábios. (STEVENS, 1998, p. 290, tradução nossa) ${ }^{3}$

Por fim, a Duração, que também é um parâmetro inédito nas investigações acústicas no seio do Projeto Norte Vogais, foi selecionada por ser indicada por Kent e Read (2015) e Barbosa e Madureira (2015) como aspecto distintivo na identificação de vogais. Entre os diversos fatores que podem influenciar a duração das vogais, receberão atenção aqui os considerados atributos duracionais inerentes: traço tenso-relaxado (longo-curto) da vogal, e altura da vogal.

Para Lehiste e Peterson (1961 apud KENT; READ, 2015, p. 184),

As vogais têm diferenças inerentes em duração. As vogais longas ou tensas possuem maiores durações do que as vogais curtas ou relaxadas, e as vogais produzidas com uma posição de mandíbula relativamente aberta (as vogais "baixas" ou "abertas") são mais longas do que as

\footnotetext{
${ }^{3}$ Do original : It is, however, possible to produce vowel categories by appropriate manipulation of the articulatory structures so as to yield points on or inside this quadrilateral. One such manipulation is modifying the rounding of the lips (STEVENS, 1998, p. 290) (tradução nossa).
} 
vogais produzidas com uma posição de mandíbula relativamente fechada (as vogais "altas" ou "fechadas").

De todo o exposto, optou-se, portanto, para o presente trabalho, realizar uma caracterização acústica mais completa das variantes das vogais médias pretônicas orais /e/ e /o/ do sistema vocálico átono da variedade do português falado em Cametá, considerando, além dos parâmetros físicos clássicos de F1 e F2, os parâmetros físicos de F3 e Duração. São analisados aqui 232 dados obtidos por meio do protocolo de leitura de texto em voz alta, cujos procedimentos metodológicos são descritos em seguida.

\section{PROCEDIMENTOS METODOLÓGICOS}

Para a realização do presente trabalho, foram aplicados os procedimentos adotados pelo projeto Norte Vogais na investigação acústica das vogais pretônicas no português falado na Amazônia Paraense (CRUZ et al., 2012; CRUZ, 2012), a saber: a) corpus padronizado; b) amostra estratificada; c) coleta de dados por meio de protocolo de leitura de texto; d) tratamento de dados no programa Praat; d) cálculo de média dos valores dos parâmetros acústicos no programa Excel para melhor visualização dos resultados.

\subsection{DESCRIÇÃO DO CORPUS}

O corpus é constituído por 45 vocábulos (Quadro 1) selecionados com base nos contextos de alta variabilidade apresentados nos estudos sociolinguísticos realizados anteriormente (RODRIGUES, 2005; RODRIGUES E ARAÚJO, 2007; CAMPOS, 2008; SOUSA, 2010).

Para a aplicação do protocolo de coleta de dados por meio de leitura de texto, os vocábulos foram inseridos em um texto intitulado $A$ marca da nacionalidade brasileira (em anexo), elaborado pelos membros do Projeto Norte Vogais.

Quadro 1 - Lista dos 45 vocábulos contendo as vogais médias alvo presentes no protocolo de leitura de texto

\begin{tabular}{|c|c|c|c|c|c|}
\hline \multicolumn{3}{|c|}{$/ \mathrm{e} /$} & \multicolumn{3}{|c|}{$/ \mathbf{o} /$} \\
\hline $\mathrm{b} / \mathrm{e} / \mathrm{bida}$ & f/e/chada & qu/e/rido & ap/o/sentado & $\mathrm{c} / \mathrm{o} /$ zinha & $\mathrm{pr} / \mathrm{o} /$ fundo \\
\hline cab/e/luda & $\mathrm{m} / \mathrm{e} /$ nino & r/e/médio & $\mathrm{b} / \mathrm{o} /$ neca & $\mathrm{d} / \mathbf{o} /$ mingo & $\mathrm{r} / \mathrm{o} /$ cambole \\
\hline c/e/rtificado & $\mathrm{p} / \mathrm{e} /$ queno & r/e/polho & $\mathrm{b} / \mathrm{o} / \mathrm{rracha}$ & h/o/spital & r/o/ndônia \\
\hline c/e/rveja & $\mathrm{p} / \mathrm{e} / \mathrm{scadores}$ & $\mathrm{s} / \mathrm{e} /$ tenta & c/o/légio & $\mathrm{m} / \mathbf{o} / \mathrm{eda}$ & t/o/alha \\
\hline d/e/zesseis & $\mathrm{pr} / \mathrm{e} / \mathrm{cisa}$ & t/e/atro & c/o/mandante & $\mathrm{m} / \mathrm{o} /$ radores & $\mathrm{t} / \mathrm{o} / \mathrm{mate}$ \\
\hline /e/mprego & $\mathrm{pr} / \mathrm{e} /$ sente & $\mathrm{t} / \mathrm{e} /$ soura & $\mathrm{c} / \mathrm{o} / \mathrm{mer}$ & $\mathrm{nam} / \mathrm{o} / \mathrm{rados}$ & \\
\hline /e/scravo & $\mathrm{pr} / \mathrm{e} /$ sidente & $\mathrm{v} / \mathrm{e} / \mathrm{ado}$ & $\mathrm{c} / \mathrm{o} / \mathrm{ruja}$ & $\mathrm{p} / \mathrm{o} /$ lícia & \\
\hline /e/stante & $\mathrm{pr} / \mathrm{e} /$ sídio & $\mathrm{v} / \mathrm{e} /$ rgonha & $\mathrm{c} / \mathrm{o} / \mathrm{stura}$ & $\mathrm{pr} / \mathrm{o} / \mathrm{cissão}$ & \\
\hline
\end{tabular}

Fonte: Verçosa $(2018$, p. 3)

\subsection{AMOSTRA ESTRATIFICADA}


Os corpora do banco de dados do projeto utilizam a mesma estratificação social adotada para as descrições sociolinguísticas: Faixa Etária (15 a 25 anos, 26 a 45 anos e acima de 45 anos), Nível de Escolaridade (Ensino Fundamental, Médio e Superior) e Sexo (Masculino e Feminino). São apresentados aqui os resultados do tratamento dos dados oriundos da primeira faixa etária.

Para participar da coleta de dados, foram selecionados 06 (seis) locutores, sendo 3 (três) masculinos e 3 (três) femininos, conforme os três níveis de escolaridade, como mostrado no Quadro 2, abaixo.

Como exigências previstas, os colaboradores deveriam ser todos paraenses natos de Cametá, ou, no caso de não terem nascido na cidade, terem ido para a localidade nos primeiros anos de vida e, de modo geral, não terem fixado residência fora da localidade por mais de 2 anos. Os genitores também deveriam ser nativos de Cametá.

Quadro 2 - Perfil dos 06 locutores gravados para o corpus

\begin{tabular}{|c|c|c|c|}
\hline LOCUTOR & SEXO & ESCOLARIDADE & IDADE \\
\hline BE91MA01_Y & Masculino & Fundamental & 15 \\
\hline BE91FA02_Y & Feminino & Fundamental & 15 \\
\hline BE91MB03_Y & Masculino & Médio & 21 \\
\hline BE91FB04_Y & Feminino & Médio & 17 \\
\hline BE91MC05_Y & Masculino & Superior & 21 \\
\hline BE91FC06_Y & Feminino & Superior & 21 \\
\hline
\end{tabular}

Fonte: Elaborado pelas autoras

\subsection{CODIFICAÇÃO}

O código do locutor mostrado no Quadro 2 acima foi previamente estabelecido e contém as seguintes informações: $\mathbf{B}$ - variedade do português brasileiro; $\mathbf{E}$ - projeto de pesquisa Norte Vogais - Segunda Versão; 9 - variedade urbana de Cametá; 1 - primeira faixa etária; $\mathbf{M}$ - sexo masculino e $\mathbf{F}$ - sexo feminino; A - nível fundamental, B - nível médio e $\mathbf{C}$ - nível superior; 01 a $\mathbf{0 6}$ - ordem numérica na amostra, ficando assim os números ímpares para o masculino (ex: masculino, fundamental - BE91MA01_Y) e os números pares para o feminino (ex: feminino, fundamental - BE91FA02_Y); Y protocolo de coleta de dados por leitura de texto.

Este mesmo código foi utilizado para identificar os vocábulos durante a atividade de extração das palavras contendo as vogais alvo da pesquisa, expandindo-se para identificar os arquivos individuais, que foram organizados em pastas individuais também identificadas pelo código de cada locutor. Assim, por exemplo, o vocábulo extraído recebeu a codificação estendida (BE91FA02_Y_borracha, BE91MB03_Y_borracha).

\subsection{TRATAMENTO DOS DADOS}


Para o tratamento dos dados, foi utilizado o programa Praat ${ }^{4}$, por meio do qual foram feitas a segmentação do sinal sonoro, a extração dos vocábulos alvo, a aplicação dos scripts de segmentação automática e correção de segmentação, bem como o script analyse_tier para tomadas de medidas acústicas.

As medidas fornecidas por este último script são tomadas da parte central da vogal alvo, e foram organizadas em planilhas do Excel, por locutor, contendo as seguintes informações: a) identificação do locutor pelo código; b) as informações extralinguísticas do locutor (sexo, escolaridade, faixa etária); c) o vocábulo alvo escrito ortograficamente; d) o tipo de vogal alvo pretônica do vocábulo que está sendo medida, se anterior ou

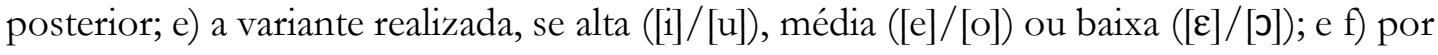
último, os valores obtidos com a tomada de medidas dos parâmetros físicos controlados: F1, F2, F3 (em Hz) e Duração (em ms).

Para os cálculos de média dos valores, os dados foram organizados em planilhas do programa Excel, sendo uma para os locutores masculinos e uma para os locutores femininos. Posteriormente, os valores de frequência de F1, F2, F3 (em Hz) e Duração (em ms) foram organizados por variante [i, e, $\varepsilon$, ว, o, u], e feitos os cálculos de média. Por fim, foram gerados os gráficos referentes aos resultados para cada parâmetro acústico, a fim de visualizar o comportamento das vogais médias pretônicas orais no espaço acústico, a partir da análise conjunta de F1 e F2, bem como a possível caracterização das vogais no que se refere à F3 e Duração. Com estes dois últimos, busca-se verificar se esses parâmetros se mostram como caracterizadores de identidade e/ou distinção das variantes tomadas como objeto de estudo na variedade do português falado na área urbana da Cidade de Cametá-PA.

Vale ressaltar que estes dois últimos parâmetros - F3 e Duração - estão sendo contemplados pela primeira vez nas investigações acústicas das vogais oriundas do Projeto Norte Vogais, não havendo, portanto, trabalhos anteriores realizados com estes parâmetros nas variedades estudadas pelo referido Projeto de Pesquisa. No entanto buscamos outras fontes que pudessem contribuir para a análise destes parâmetros.

Foram analisados 232 dados, cuja distribuição por locutor encontra-se na Tabela 1 abaixo.

Tabela 1 - Tamanho do corpus analisado - Total de 232 dados

\begin{tabular}{c|ccc|ccc|c}
\hline \multirow{2}{*}{ LOCUTOR } & \multicolumn{3}{c|}{ VARIANTES } & \multicolumn{3}{c|}{$\begin{array}{c}\text { VARIANTES } \\
\text { POSTERIORES }\end{array}$} & \multirow{2}{*}{ TOTAL } \\
\cline { 2 - 6 } & {$[\mathbf{i}]$} & {$[\mathbf{e}]$} & {$[\boldsymbol{\varepsilon}]$} & {$[\mathbf{u}]$} & [ o ] & [ o ] & \\
\hline BE91MA01_Y & 4 & 16 & 2 & 0 & 9 & 9 & 40 \\
BE91FA02_Y & 2 & 17 & 4 & 3 & 10 & 5 & 41 \\
BE91MB03_Y & 3 & 15 & 3 & 3 & 10 & 4 & 38 \\
BE91FB04_Y & 1 & 16 & 4 & 2 & 9 & 7 & 39
\end{tabular}

${ }^{4}$ http://www.fon.hum.uva.nl/praat/. 


\section{das Letras}

$\begin{array}{llllllll}\text { BE91MC05_Y } & 3 & 14 & 4 & 1 & 8 & 5 & 35 \\ \text { BE91FC06_Y } & 1 & 20 & 1 & 6 & 7 & 4 & 39\end{array}$

Fonte: Elaborado pelas autoras

\section{RESULTADOS}

Apresenta-se, nesta seção, os resultados em três subseções: 4.1) o comportamento das vogais médias pretônicas e suas variantes no espaço acústico segundo os parâmetros de F1 (em Hz) e F2 (em Hz); 4.2) a caracterização acústica das variantes considerando o parâmetro de $\mathrm{F} 3(\mathrm{em} \mathrm{Hz}) ; 4.3)$ a caracterização acústica das variantes segundo o parâmetro de Duração (em ms).

\subsection{ESPAÇO ACÚSTICO DAS VOGAIS MÉDIAS PRETÔNICAS - F1 (Hz) E F2 $(\mathrm{Hz})$}

A Figura 3 apresenta o espaço acústico das vogais médias pretônicas orais /e/ e /o/ e suas variantes no português falado na área urbana da cidade de Cametá-PA, oriundo dos dados de locutores masculinos e femininos com idades entre 15 e 25 anos.

Figura 3 - Espaço acústico das vogais médias pretônicas /e/ e /o/ com dados da primeira faixa etária (15 a 25 anos) - sexo feminino (a) e sexo masculino (b) - Total de 232 dados

(a)

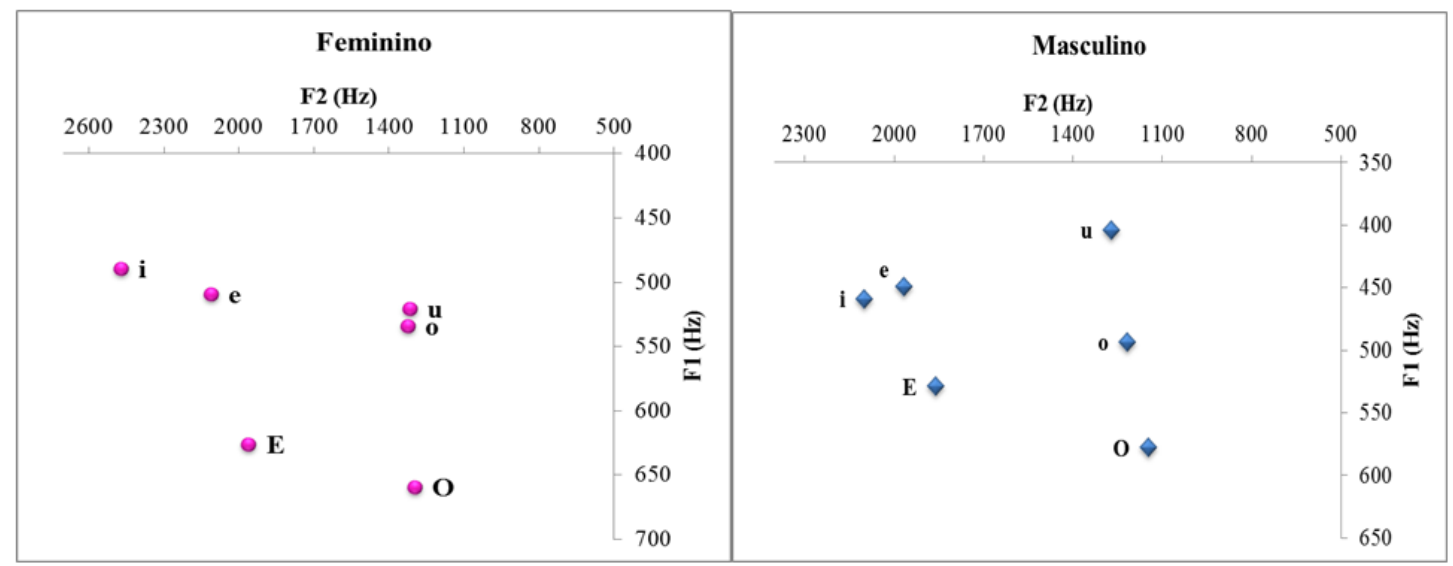

Fonte: Elaborado pelas autoras

O espaço acústico da fala feminina (a) mostra que as variantes anteriores [i] e [e] se encontram mais distantes (talvez indicando menos variação), e as posteriores $[\mathrm{o}]$ e $[\mathrm{u}]$ encontram-se no mesmo espaço acústico (talvez indicando mais variação). $\mathrm{O}$ oposto ocorre na fala masculina, pois as variantes anteriores [i] e [e] se encontram mais próximas (talvez indicando mais variação), e as posteriores $[\mathrm{o}]$, [0] e [u] mais distantes em relação a $\mathrm{F} 1$, porém em espaço semelhante em relação a F2 (talvez indicando menos variação). 
A variante alta posterior $[\mathrm{u}]$ apresenta uma outra particularidade, pois tanto na fala feminina quanto na fala masculina, tende mais à centralização. As variantes baixas [E] e [j] se encontram distantes das variantes médias e altas na fala feminina. Enquanto se observa que, na fala masculina, as variantes anteriores [i], [e] e [ $[\varepsilon]$ se encontram mais próximas, e pode-se notar ainda que a variante alta [i] apresenta F1 mais baixo que a variante média [e].

\subsection{CARACTERIZAÇÃO ACÚSTICA CONSIDERANDO O PARÂMETRO DE F3 $(\mathrm{Hz})$}

Como exposto na seção 2, o terceiro formante tem papel importante na caracterização acústica de vogais, na medida em que é um modo de constrição no trato vocal que pode determinar mudanças nas frequências dos dois primeiros formantes. Com o arredondamento dos lábios, tem-se o alongamento do trato vocal e, consequentemente, o abaixamento das frequências dos formantes, mostrando que, quanto maior for o comprimento do trato vocal, mais baixas serão as frequências de F3. Por isso, as vogais arredondadas tendem a frequências de F3 mais baixas que as vogais não-arredondadas.

Quanto ao parâmetro de F3 (Hz), os resultados são mostrados na Figura 4 abaixo.

Figura 4 - Médias das frequências de F3 (Hz) das variantes das vogais alvo com dados da primeira faixa etária (de 15 a 25 anos) - sexo feminino (c) e sexo masculino (d) - Total de 232 dados

(c)

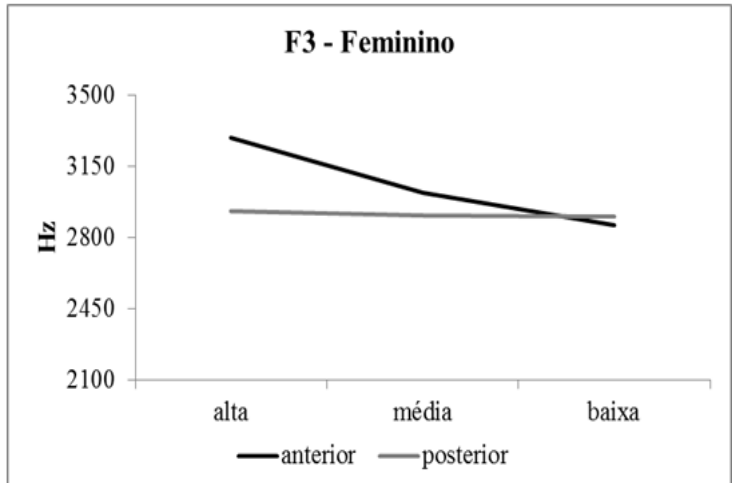

(d)

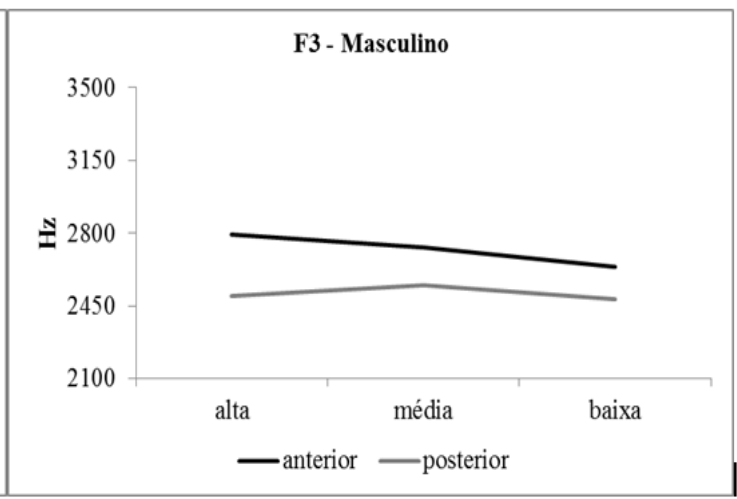

Fonte: Elaborado pelas autoras

Os resultados da Figura 4 mostram o movimento da linha do terceiro formante (F3 - Hz), pelos quais é possível identificar claramente que as variantes posteriores têm frequências mais baixas (em cinza) que as anteriores (em preto), tanto na fala feminina (c) quanto na fala masculina (d), pelo que é possível confirmar que as variantes com frequências mais baixas são as mais arredondadas.

No que se refere à caracterização acústica, conclui-se que o parâmetro de $\mathrm{F} 3(\mathrm{~Hz})$ funciona como um parâmetro de identidade entre as variantes, uma vez que há uma 


\section{das Letras}

proximidade muito grande entre as frequências dessas variantes, seja na fala masculina ou feminina. Com isso, observa-se que não se tratam de fonemas diferentes, mas de realizações de um mesmo fonema no nível subjacente.

\subsection{CARACTERIZAÇÃO ACÚSTICA CONSIDERANDO O PARÂMETRO FÍSICO DE DURAÇÃO (ms)}

$\mathrm{Na}$ busca de verificar o parâmetro de duração como um aspecto distintivo na identificação de vogais, apresentam-se a seguir os resultados na Figura 5.

Figura 5 - Médias de duração (ms) das variantes das vogais alvo com dados da primeira faixa etária (de 15 a 25 anos), tanto do sexo feminino (e) quanto do masculino (f) - Total de 232 dados

(e)

(f)

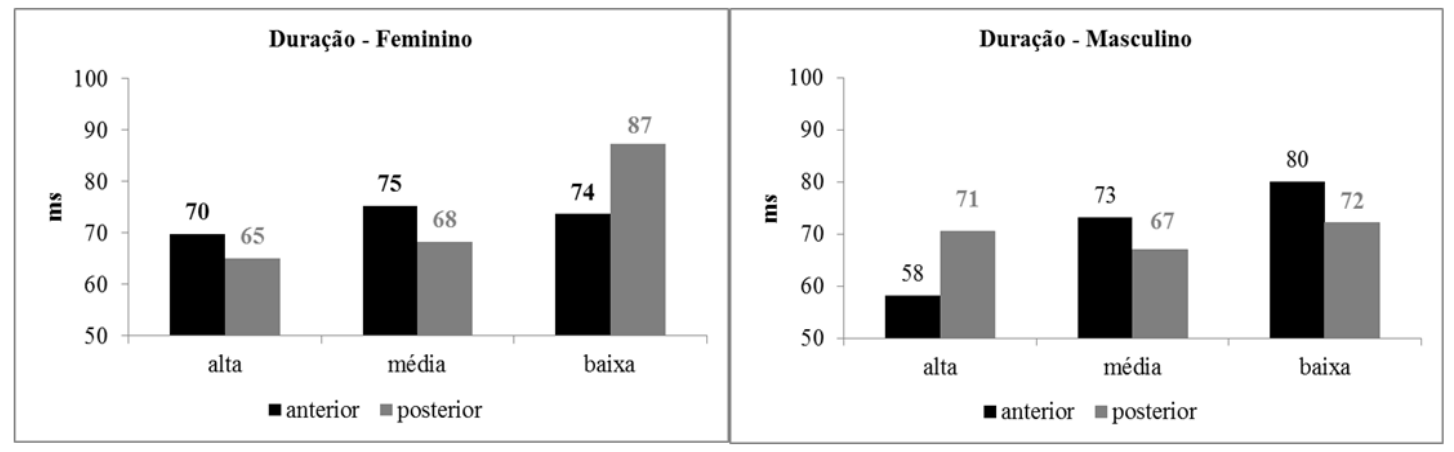

Fonte: Elaborado pelas autoras

Observa-se nos resultados apresentados na Figura 5 que as medidas de duração das variantes obedecem ao previsto para os dois aspectos duracionais inerentes às vogais, ou seja, o traço tenso-relaxado (longo-curto) da vogal, e altura da vogal.

$\mathrm{Na}$ fala feminina (e), a variante mais longa é a variante baixa posterior [0] com $87 \mathrm{~ms}$ (em cinza), e a mais curta é a variante alta posterior $[\mathrm{u}]$ com $65 \mathrm{~ms}$ (em cinza). Na fala masculina (f), a variante mais longa é a variante baixa anterior $[\varepsilon]$ com $80 \mathrm{~ms}$; e a variante mais curta é a variante alta anterior [i] com 58ms.

Do exposto, comprova-se que as variantes abertas e baixas são mais longas que as variantes médias e altas, comportando-se assim como um parâmetro que caracteriza as vogais por seus aspectos duracionais capazes de estabelecer distinções entre as variantes.

\section{DISCUSSÃO DOS RESULTADOS}

De todo o exposto, a análise de F1 e F2 mostrou que a vogal média pretônica anterior /e/ sofre mais variação na fala masculina; e a vogal média pretônica posterior /o/ sofre mais variação na fala feminina. 
Quanto ao parâmetro de F3, relacionado ao arredondamento dos lábios, confirmou-se que as frequências mais baixas de F3 são das variantes posteriores. No entanto a variante anterior baixa também mostrou tendência ao arredondamento na fala feminina por apresentar frequência bem próxima da variante posterior baixa. De modo geral, concluiu-se que F3 se mostra como parâmetro de identidade das variantes como realização de um mesmo fonema do nível subjacente.

Por fim, a duração, embora não seja uma propriedade da onda sonora, mas uma medida de tempo, é um parâmetro importante para a caracterização acústica das vogais. Os resultados mostraram que, tanto na fala masculina quanto na fala feminina, as variantes altas e médias têm duração mais curta que as variantes baixas.

\section{CONSIDERAÇÕES FINAIS}

Apresentaram-se neste trabalho os resultados preliminares obtidos com a caracterização acústica do sistema vocálico átono do português falado na variedade linguística da área urbana da cidade de Cametá/PA (SOUSA, em andamento), abordando mais especificamente as variantes das vogais médias pretônicas /e/ e /o/. Trata-se de uma caracterização acústica mais completa das vogais alvo que acrescenta, além da elaboração clássica do espaço acústico a partir das medidas de F1 e F2, tomadas de medidas de F3 e Duração.

O corpus analisado compreendeu 232 dados de leitura de vocábulos contendo contexto das vogais alvo produzidas por seis locutores nativos da variedade cametaense estratificados socialmente e que participaram de um protocolo de coleta de dados que envolvia leitura em voz alta.

O parâmetro de F3 se mostrou como parâmetros de identidade das variantes, demonstrando que o nível acústico é um espelho do nível fonológico, uma vez que a proximidade entre as médias das frequências das variantes demonstra que não se tratam de fonemas diferentes, mas das diferentes realizações de um mesmo fonema. Quanto ao espaço acústico formado com as médias de F1 e F2, observou-se maior proximidade entre as variantes altas e médias, e maior distância entre as variantes médias e baixas. Quanto à Duração, verificou-se que as variantes abertas e baixas são mais longas que as variantes médias e altas, comportando-se assim como um parâmetro que caracteriza as vogais por seus aspectos duracionais capazes de estabelecer distinções entre as variantes.

Portanto os resultados ora alcançados demonstram a importância dos estudos acústicos na variedade selecionada, uma vez que foram abordados dois parâmetros acústicos inéditos e os resultados, diferentes das hipóteses levantadas, podem contribuir sobremaneira para o avanço dos estudos do português falado na Amazônia Paraense.

\section{APÊNDICE: Texto elaborado para a coleta de dados}

\section{A marca da nacionalidade brasileira}


No ano de 2014 foi realizado um dos mais ricos e belos eventos esportivos: a Copa do Mundo de futebol, sediada no Brasil. Desde a copa de setenta com a conquista do tricampeonato, a seleção brasileira passou a ser mais querida por todos, principalmente porque na equipe tinha os "três mosqueteiros": Pelé, Garrincha e Tostão, formando assim aquele velho slogan: "A taça do mundo é nossa". Desde o pequeno menino até o mais ancião, desde o sobrinho até o vovozão, do comandante ao aposentado, é percebida a paixão desenfreada pelo futebol, e acima de tudo, pela seleção canarinho.

Em dias de jogos do Brasil "tudo é fechado". Como num domingo os namorados deixam de visitar suas amadas, as costureiras param de costurar, colégios param de funcionar, a polícia para em frente a qualquer televisor espalhado pelas ruas, e até mesmo os hospitais entram no ritmo da copa. É como se fosse uma procissão verde e amarela, na qual até o nosso presidente participa.

É uma paixão avassaladora que conquista o país inteiro desde Oiapoque ao Chuí, de Rondônia ao Piauí. As senhoras se encontram na cozinha, as meninas com suas bonecas, nos prédios o morador da direita comenta com o da esquerda que já irá começar o jogo. Todos em frente à TV para acompanhar o tal episódio. Há até a maior oferta de empregos terceirizados como a venda de bebidas, cervejas, refrigerantes e até remédios para possíveis "chiliques".

Nesta época, os jogadores escalados treinam como escravos, reza a lenda do pescador que eles chegam a treinar até dezesseis horas por dia. Tirar o domingo para descansar? Sono profundo? Nem pensar. Comer demais? Jamais. É preciso estar sempre alerta a tudo, como em uma peça de teatro. E nem ouse a pensar que a torcida perdoará um jogo perdido. É a maior vergonha para os jogadores que são xingados de tudo: burros, veados, com direito até a um certificado de incompetência, mas apesar de tudo isso os jogadores não devem nem por um segundo imaginar jogar a toalha.

Já o técnico sofre a pior das cobranças, além de ter que treinar os jogadores dia e noite, noite e dia, tem de aguentar os xingamentos de todos os tipos e passar por situações constrangedoras, servindo de alvo para ovos, tomates, repolhos, rocamboles, entre outros alimentos de nossa culinária brasileira.

É necessário também ter um grande cuidado com os Hermanos cabeludos argentinos, que parecem mais corujas de olhos bem abertos atrás de marcar logo um gol. É preciso cortá-los do meio do caminho com uma tesoura chamada raça e determinação por parte de nossos craques. Passar uma bela borracha em todos os adversários, pois assim a nossa nação se alegrará. A té o valor de nossas moedas poderá subir. Vamos apoiar a nossa seleção. Se o Brasil não ganhar novamente, é possível até que todos os meliantes fujam revoltados dos presídios. Temos que trazer o caneco para exibirmos como um presente em nossa estante.

\section{REFERÊNCIAS}

CAMPOS, Socorro. Alteamento vocálico em posição pretônica no português falado no município de Mocajuba-Pará. 2008. 202 f. Dissertação (Mestrado em Letras) - Universidade Federal do Pará, Belém, 2008. 
CRUZ, Regina. Projeto de Pesquisa Brazilian Amazon Portuguese Vowel System: acoustic analysis (Processo BEX1754Q10-6). Brasília: CAPES/Fulbright; New York: New York University. Relatório Técnico-Científico, 2011.

et al. Alteamento vocálico das médias pretônicas no português falado na Amazônia paraense. In: LEE, Seung Hwa (Org.). Vogais além de Belo Horizonte. Belo Horizonte: Faculdade de Letras da UFMG, 2012, p. 194-220.

. Vogais na Amazônia Paraense. Alfa: Revista de Linguística (UNESP. Online), v. 56, p. 945-972, 2012b.

KENT, R. D.; READ, C. Análise acústica da fala. Tradução de Alexsandro Meireles. São Paulo: Cortez, 2015.

MORAES, Marlúcia Lopes. As vogais médias pretônicas /e/ e /o/ no português falado na zona rural do Município de Cametá: uma caracterização acústica. Cametá: UFPA/CUNTINS, 2015 (Trabalho de Conclusão de Curso).

RODRIGUES, Doriedson. Da zona urbana a rural/ entre a tônica e a pretônica: alteamento /o/ $>[\mathrm{u}]$ no português falado no município de Cametá/Ne paraense: uma abordagem variacionista. 2005. 387 f. Dissertacao (Mestrado em Letras) - Universidade Federal do Pará, Belém, 2005.

; ARAÚjO, Marivana dos Prazeres. As vogais médias pretônicas / e / e / o / no português falado no município de Cametá/PA - a harmonização vocálica numa abordagem variacionista. Cadernos de Pesquisa em Linguística, Variação no Português Brasileiro, v. 3, Porto Alegre, nov./2007, p. 104-126.

SILVA, Ana Carolina Reis da. Vogais médias pretônicas de Belém (PA): análise qualitativa. 2014. Trabalho de Conclusão de Curso (Licenciatura em Letras - Língua Portuguesa) Universidade Federal do Pará, Belém, 2014.

SOUSA, Josivane. A variação das vogais médias pretônicas no português falado na área urbana do município de Belém-PA. 2010. 209f. Dissertação (Mestrado em Letras) - Universidade Federal do Pará, Belém, 2010.

- Sistema vocálico pretônico do português falado na cidade de Cametá-PA: caracterização acústica. Início: 2016. Tese em andamento (Doutorado em Letras: Estudos Linguísticos e Teoria Literária), UFPA.

SOUZA, Gisele Braga. Caracterização acústica das vogais médias pretônicas no português falado em Barcarena-PA. 2015. Dissertação (Mestrado em Letras) - Universidade Federal do Pará, Belém: UFPA.

; REIS, Mara Sueny da Costa; MORAES, Marlúcia Lopes; CRUZ, Regina Célia Fernandes. A F0 intrínseca como parâmetro acústico de identidade das variantes das vogais médias pré-tônicas do português falado na Amazônia paraense. In: MOUTINHO, Lurdes de Castro; COIMBRA, Rosa Lídia; REI; Elisa Fernández (Coords). Estudos em variação geoprosódica. Aveiro: UA Editora, Universidade de Aveiro, p. 33-52, 2015.

STEVENS, Kenneth N. Acoustic phonetics. Cambridge: MIT Press, 1998.

VERÇOSA, Victor. Caracterização acústica das vogais médias pretônicas / e/ e /o/ do português falado na área urbana da cidade de Cametá-PA: análise dos dados de fala lida. Relatório Final de Bolsa de Iniciação Científica. Belém, UFPA, 2018 (BOLSISTA PIBIC/INTERIOR). 


$\left\{\begin{array}{l}\text { Revista } \\ \text { ACor } \\ \quad \text { das Letras }\end{array}\right.$

Recebido em: 28/02/2019

Aprovado em: 07/06/2019

Publicado em: 28/09/2019 